\title{
Placental abruption and preterm premature rupture of membranes: How much frequent?
}

\author{
${\text { Emre Ekmekci }{ }^{*} \text { and Servet Gencdal }}^{2}$ \\ ${ }^{1}$ Sanliurfa Education and Research Hospital, Department of Obstetrics and Gynecology, Maternal-Fetal Medicine Unit, Sanliurfa, Turkey \\ ${ }^{2}$ Izmir Katip Celebi University Atatürk Education and Research Hospital, Department of Obstetrics and Gynecology, Izmir, Turkey
}

\begin{abstract}
Purpose: To describe the placental abruption rate in patients with preterm premature rupture of membranes (PPROM) during 24-34 weeks gestation

Material and methods: Patients admitted due to PPROM during 24-34 weeks of gestation and followed in clinic are included in the study. Primary aim of the study was to describe the placental abruption rate in study group. Secondary aim was to describe the delivery indications after PPROM in the study group.

Results: Total 67 patients are included in the study. Placental abruption rate was 0,059\%(4/67). Delivery indications were preterm labor, fetal distress, placental abruption, cordon prolapsus, and chorioamnionitis.
\end{abstract}

Conclusion: Abruptio placenta (AP) is not a rare complication after PPROM. Clinicians should be cautious in follow up of patients after PPROM due to maternal and fetal morbidity.

\section{Introduction}

Preterm premature rupture of membranes (PPROM) occurs in $3 \%$ of all pregnancies and is one of the leading causes of all preterm deliveries with $30-40 \%$ [1]. Also, the gestational week at membrane rupture is less than 27 weeks at 0.5 percent and between 27 to 34 weeks at 1 percent of all pregnancies [2]. Conservative management is the preferred management strategy for PPROM patients between 24-34weeks. During conservative management of PPROM, patients are at any time subject to experiencing a wide range of different pregnancy complications, including chorioamnionitis, placental abruption or preterm birth secondary to preterm labor alone [3].

Placental abruption(AP) is a major cause of maternal and perinatal morbidity, and perinatal mortality. The perinatal mortality is approximately 20 times higher after placental abruption [4]. Also the majority of perinatal deaths (up to 77 percent) occur suddenly, before delivery. Postnatal deaths are primarily related to prematurity [5]. Maternal potential consequences of abruption are primarily related to the severity of the placental separation and severity of hemorrhage, while the risks to the fetus are related to both the severity of the separation and the gestational age at abruption [6].

Several studies have suggested that PPROM is a major risk factor for placental abruption [7]. This association is becoming more important because viability chance of babies is getting earlier with improving technology. Thus, the American Obstetric and Gynecological Association has, in any case of PPROM, recommended special awareness with respect to placental abruption [8]. In this study we analyzed the pregnancy outcomes of PPROM patients between 24-34weeks gestation and the rate of placental abruption in patients that we have followed in our clinic.

\section{Material and methods}

This retrospective descriptive study is conducted in Department of Obstetrics and Gynecology, Maternal-Fetal Medicine Unit, Sanliurfa Education and Research Hospital, Sanliurfa, Turkey. Retrospectively collected data is acquired from patients who have been hospitalized due to PPROM during 24-34 weeks gestation, between September 2017 and April 2018. The unit is a busy tertiary centre at east of Turkey getting referral patients from the region with about 45000 deliveries in a year. The patients included are all inpatients and are followed in clinic. Patients who are delivered due to indications not related to PPROM, like severe preeclampsia or abnormal obstetrical Doppler are not included in the study. If delivery is started spontaneously in 24 hours after membrane rupture, they are defined as preterm labor and were not included in the study. All patients were followed in clinic up to 34 th gestational week unless there was an additional indication of termination.

Demographic data of patients, gestational age at hospitalization, delivery time, delivery indications and total follow-up time to delivery of each case are recorded. Obstetrical history of each patient is taken about the presence of a previous abruptio placenta history. The presence of clinical chorioamnionitis is evaluated. AP rate is calculated. Diagnosis of placental abruption is made if the abruption is confirmed intraoperatively. Mean follow-up time to delivery and delivery indications for the study group are reported.

${ }^{\star}$ Correspondence to: Servet Gencdal, MD, Izmir Katip Celebi University Atatürk Education and Research Hospital, Department of Obstetrics and Gynecology, Izmir, Turkey

Key words: Abruptio placenta, PPROM, peripartum hemorrhage

Received: April 04, 2018; Accepted: April 19, 2018; Published: April 21, 2018 


\section{Results}

During this period total 82 pregnant patients were admitted for preterm premature membrane rupture during 24-34 weeks of gestation. 12 patients rejected hospitalization and were discharged prior to 34th gestational week. Two patients were delivered due to abnormal umbilical artery Doppler and fetal growth retardation. One patient was delivered due to severe preeclampsia and these are excluded from the study group. Total 67 patients are included in this study group.

Mean maternal age was $28 \pm 4.3$ years. Median gravida was three. Mean body mass index was 26.3. Median gestational age at hospitalization was 32 weeks. 65 pregnancies were singleton and two were twin pregnancies. Mean follow-up time to delivery was $7.2 \pm 3.5$ days (2 - 37 days). Delivery indications and distribution are reported in Table 1. Total 13 patients have been followed up to 34th weeks. The delivery started spontaneously or verified by cesarean section due to complications before 34 th weeks at 54 patients. Three patients were delivered due to peripartum hemorrhage due to placental abruption. Total five patients were delivered due to fetal distress. Intraoperatively concealed placental abruption is detected at two of these patients. AP diagnosed patient's data and follow-up time of each are reported in Table 2.37 patients are delivered vaginally and 30 patients are delivered by cesarean section, 19 of them due to previous cesarean section history. All babies are delivered alive, no intrauterine fetal death have been resulted.

\section{Discussion}

Although patients are candidates for various complications after membrane rupture, chorioamnionitis and placental abruption are the major hazardous problems because they are associated with both maternal and neonatal morbidity, mortality. In our study group initial AP diagnosis rate was $4.47 \%$ before delivery and this rate is consistent with previous studies evaluated palcental abruption after membrane ruptures at all gestational ages [7]. However intraoperative concealed abruption is detected at two patients who were delivered due to fetal distress. Placental abruption should be kept in mind in case of fetal distress during follow-up of patients with PPROM. This association requires more attention and should be searched more.

The studies evaluating the AP rate after membrane rupture are reporting inconsistent findings. The major reason for these discordance seems the different study populations selected for the study. Also, the description of AP differs in different study groups. Major et al reported AP rate as 5\% after PPROM at 756 patients between 20-36 weeks [9]. Markhus et al reported AP rate as $1.1 \%$ after PPROM at 3077 patients less than 37 weeks. Also they reported AP rate as $1.7 \%$ after membrane rupture over 37 weeks gestation. But they excluded pregnancies with fetal death and low Apgar with babies. This invents a variation in the description of AP [10]. Different studies report a higher rate of AP at preterm labor patients without membrane rupture than patients with PPROM. This may be due to different mechanisms causing to AP in different two situations [11-13].

The primary target group patients after PPROM is 24-34 weeks gestation pregnancies. Because this group is the object for follow-up. After 34 weeks of gestation with PPROM, induction of labor is the recommended management [8]. In this study we have only included 24-34weeks pregnancies and our results belong to this group. This is a major strength for our study. Maternal excessive blood loss leading hypovolemic shock, DIC renal failure, adult respiratory distress syndrome, multiorgan failure, peripartum hysterectomy and, rarely, death can occur after AP [14]. Also, in population-based studies, the perinatal mortality rate is ranged from 3 to 12 percent and intrauterine asphyxia is an other important issue $[15,16]$.

Considering the high maternal and fetal mortality risk associated with AP, we conclude that the results of our study of may be useful about the controversial issue about follow-up of patients after PPROM, hospitalized or outpatient. Because of the risk of AP such as $7.4 \%$ (concealed and revealed) during follow-up, this group of patients should be recommended for hospitalization.

\section{Conclusion}

In conclusion, strengths of the present study is its limited study population between 24-34 weeks gestation that's the primary selected population for follow-up after PPROM, description of placental abruption in revealed or concealed types. According to our research on Pubmed, this is the first study evaluating AP in two separate types. Some study limitations should be acknowledged such as the sample size, lack of AP rate in normal population and retrospective collection of data. Despite this restraints, our results touch upon an important issue in perinatal medicine. Thus, further larger and more extensive studies are required in this field.

Table 1. Delivery Indications, Delivery Type and Distribution of Patients.

\begin{tabular}{|c|c|c|}
\hline Delivery indications & Number of patients & Vaginal delivery / Cesarean section \\
\hline Preterm labor & 43 & $29 / 14$ \\
\hline 34th week of gestation & 13 & $8 / 5$ \\
\hline Fetal distress & 5 & $0 / 5$ \\
\hline Placental abruption & 3 & $0 / 3$ \\
\hline Cordon prolapsus & 2 & $0 / 2$ \\
\hline Chorioamnionitis & 1 & \\
\hline
\end{tabular}

Table 2. Distribution of Patients with Placental Abruption.

\begin{tabular}{|l|c|c|c|c|c|}
\hline & Type of AP & GA at delivery & Gravida & Number of fetuses & Follow-up time to AP \\
(days) & BMI & Singleton \\
\hline Case 1 & Revealed AP & 29 & 3 & Singleton \\
\hline Case 2 & Revealed AP & 31 & 5 & Singleton \\
\hline Case 3 & Revealed AP & 32 & 2 & Singleton \\
\hline Case 4 & Concealed AP & 31 & 1 & 24 \\
\hline Case 5 & Concealed AP & 32 & 3 & Singleton \\
\hline
\end{tabular}

Abbreviations: AP, abruptio placenta; GA, gestational age; BMI, body mass index. 


\section{References}

1. Mercer BM (2005) Preterm premature rupture of the membranes: current approaches to evaluation and management. Obstet Gynecol Clin North Am 32: 411-428. [Crossref]

2. Jantien L van der Heyden (2014) Preterm prelabor rupture of membranes: different gestational ages, different problems. Thesis.

3. Practice Bulletin No. 160 Summary: Premature Rupture of Membranes (2016) Obstet Gynecol 127: 192-194. [Crossref]

4. Tikkanen M, Luukkaala T, Gissler M, Ritvanen A, Ylikorkala O, et al. (2013) Decreasing perinatal mortality in placental abruption. Acta Obstet Gynecol Scand 92: 298-305. [Crossref]

5. Aliyu MH, Salihu HM, Lynch O, Alio AP, Marty PJ (2012) Placental abruption, offspring sex, and birth outcomes in a large cohort of mothers. J Matern Fetal Neonatal Med 25: 248-252. [Crossref]

6. Oyelese Y, Ananth CV (2006) Placental abruption. Obstet Gynecol 108: 1005-1016. [Crossref]

7. Markhus VH, Rasmussen S, Lie SA, Irgens LM (2011) Placental abruption and premature rupture of membranes. Acta Obstet Gynecol Scand 90: 1024-1029. [Crossref]

8. ACOG Committee on Practice Bulletins-Obstetrics (2007) ACOG Practice Bulletin No. 80: premature rupture of membranes. Clinical management guidelines for obstetriciangynecologists. Obstet Gynecol 109: 1007-1019. [Crossref]
9. Major CA, de Veciana M, Lewis DF, Morgan MA (1995) Preterm premature rupture of membranes and abruptio placentae: is there an association between these pregnancy complications? Am J Obstet Gynecol 172: 672-676. [Crossref]

10. Markhus VH, Rasmussen S, Lie SA, Irgens LM (2011) Placental abruption and premature rupture of membranes. Acta Obstet Gynecol Scand 90: 1024-1029. [Crossref]

11. Spinillo A, Capuzzo E, Colonna L, Solerte L, Nicola S, et al. (1994) Factors associated with abruptio placentae in preterm deliveries. Acta Obstet Gynecol Scand 73: 307-312. [Crossref]

12. Sheiner E, Shoham-Vardi I, Hadar A, Hallak M, Hackmon R, et al. (2002) Incidence, obstetric risk factors and pregnancy outcome of preterm placental abruption: a retrospective analysis. J Matern Fetal Neonatal Med 11: 34-39. [Crossref]

13. Johanzon M, Odesjö H, Jacobsson B, Sandberg K, Wennerholm UB (2008) Extreme preterm birth: onset of delivery and its effect on infant survival and morbidity. Obstet Gynecol 111: 42-50. [Crossref]

14. Tikkanen M (2011) Placental abruption: epidemiology, risk factors and consequences Acta Obstet Gynecol Scand 90: 140-149. [Crossref]

15. Downes KL, Shenassa ED, Grantz KL (2017) Neonatal Outcomes Associated With Placental Abruption. Am J Epidemiol 186: 1319-1328. [Crossref]

16. Tikkanen M (2011) Placental abruption: epidemiology, risk factors and consequences Acta Obstet Gynecol Scand 90: 140-149. [Crossref]

Copyright: (C2018 Ekmekci E. This is an open-access article distributed under the terms of the Creative Commons Attribution License, which permits unrestricted use, distribution, and reproduction in any medium, provided the original author and source are credited. 